\title{
Valorizing the Museum Education through Organizing and Doing Exhibitions for Students in Context of Interaction between Museum-Family-Community-Educational Institution
}

\author{
Tatiana Filipski \\ UPSC, UTM, Chisinau, Republic of Moldova \\ Email: tanyafilipski@mail.com
}

How to cite this paper: Filipski, T. (2021). Valorizing the Museum Education through Organizing and Doing Exhibitions for Students in Context of Interaction between $\mathrm{Mu}$ seum-Family-Community-Educational Institution. Creative Education, 12, 2518-2528. https://doi.org/10.4236/ce.2021.1211188

Received: September 13, 2021

Accepted: November 7, 2021

Published: November 10, 2021

Copyright $\odot 2021$ by author(s) and Scientific Research Publishing Inc. This work is licensed under the Creative Commons Attribution International License (CC BY 4.0).

http://creativecommons.org/licenses/by/4.0/

(c) (i) Open Access

\begin{abstract}
The article represents a theoretical study that reflects some conceptual aspects and emphasizes some visions of the research about organizing and displaying of museal exhibition, which focused on school-museum-family-community collaboration. In this study are represented the conditions, components, principles, and other aspects of organizing and showing of museum exhibitions, which focused on the museum education built in the context of school-museum-family-community collaboration. In the study are reflected the necessary conditions for organizing and conducting the museum exhibition, basic components of museum exhibition design, main types of organising and exposing a modern museum exhibition, the museum exhibitions are classified by the type of museum patrimony available. Also, are emphasized: The communicative properties of the museum artefact and principles of grouping of museum objects that constitute the museum exhibition, as well as their correlation to the criteria of learning classification; the rules of driving the perception of information as promoted by the adepts of Gestalt Theory; the pedagogic condition of conducting the education in the museum facilities. Meanwhile, are presented the applicative didactical forms and methods for conducting the activities within the Institutional Project "Creation of education partnership in promoting the museum national and universal heritage from the perspective of pupil's and student's museum education", including a piece of our research with the subjects of the same project, conclusions, and recommendations. As a result of our research, we find that the museum institution in interoperability with school-family-community partnership offers
\end{abstract}


theoretical and practical solutions for educating a harmoniously developed personality via knowledge of its authentic values, and the activity of museum education in our country has to be developed in the educational institutions as well as in the museums, involving the parents and the community.

\section{Keywords}

Museum, Museum Education, Museum Exhibition, Values, Museum Exhibit, Museum Heritage

\section{Introduction}

The XXI century museum is the cultural institution which through its means and facilities builds new learning techniques, generating favorable conditions for young generation education and culture spreading. The process of museum education can be performed more efficiently only via collaboration and cooperation between family and different social institutions focused on promoting the cultural, spiritual, and moral heritage. The main product of the museum work with the audience is the museum exhibition, which acts as education, communication, communication, socialization, and value orientation of the society.

\section{Ease of Use}

First, we are underlining some envisions of some research regarding the organizing and conducting the museum exhibitions. Museum exhibition means the exposure and demonstration of museum objects and collections in the museum area scientifically justified and compositional structured, with attached comments, artistically decorated, emphasizing the museum institution image and specific activity (Myagtina, 2010).

The exhibition is perceived as a true reflection of the reality (Ploșniță, 2010). This perception is developed using some exposure methods, using reconstructions and mock scenery.

Similar meaning of museum exhibition is shared by different researchers, stating that museum exhibition is an exposure and demonstration of compositionally structured, technically designed (Troyanskaya, 2007), commenting scientifically museum artefacts which develop the museum image specific for anthropic evolution linked to natural and socio cultural.

Given that, organizing and conducting of museum exhibition suppose a cross synthesis of creative and scientific process with the technologic one, in which are involved the museologists, designers, psychologists, professors, engineers, $3^{\text {rd }}$ party staff etc., aiming the valorization, exploration and testing some innovative methods, in order to impact maximally the museum audience. Regarding the organizing and conducting of students aiming museum exhibitions, these require the coordination and consulting of teaching staff in order to correlate 
those to content and curriculum of institutions disciplines. Researchers consider that for organizing and conducting student audience aimed museum exhibitions should be met the following conditions (Myagtina, 2010):

- clarification of exhibition thematic;

- access to thematic museum collections;

- staff of specialists competent in the exposed subject;

- available exposure facilities;

- well-developed technical and material ground.

Meanwhile, the design of any type of museum exhibition is based on several components as (Myagtina, 2010):

- the scientific design, during which is emphasized the concept and content of exhibition;

- the artistic design, supposes the pictural-artistic approach of the exhibition;

- technical and material design, focusing the places of exposed artefacts, attached text, appliances and technical solutions, additional components of the exposition.

Can be branched the following main types of modern museum exhibitions (Shcherbina, 2011) (Figure 1):

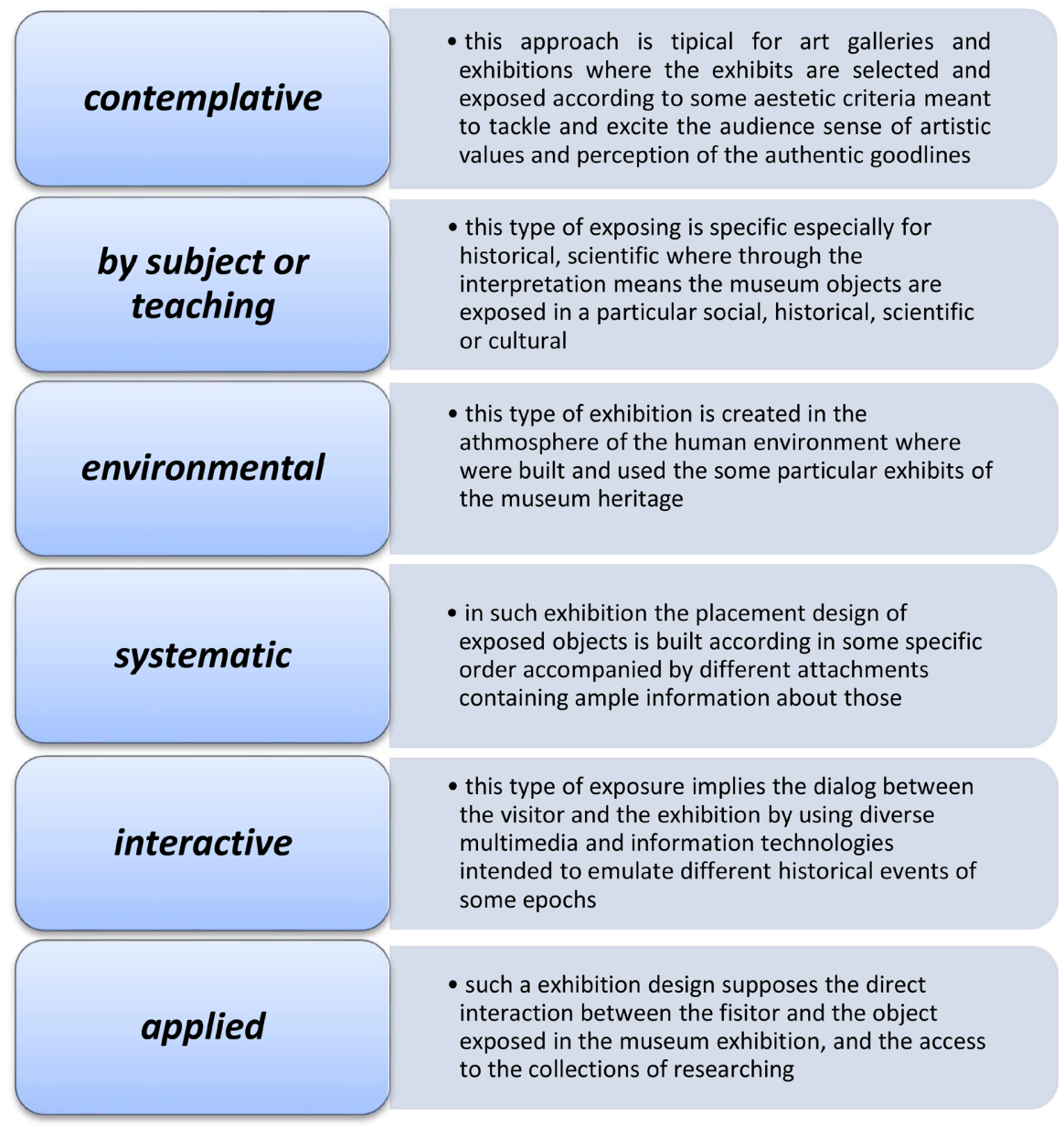

Figure 1. The main principles of modern museum exhibition. 
All types of the museum exhibitions represent an important way of the incarnation and optimal exposure of the museum offers, a method of an efficient implementation of its cultural and educational potential, interaction and communication facilities with museum audience.

The types of museum exhibitions, emphasized according to presentation system and the available museum heritage (Pop, 2016), can be spotted by the presentation system: permanent, temporary and mobile exhibitions.

According to the Dutch museologists states that the permanent exhibition of some museum is the core constituent of its heritage, offering the representative image of the collection that can be watched any time (Aarts, 2010).

In accordance with all related, our researchers specifies that the permanent exhibition can include the subject exhibition i.e., basic exhibition of the museum institution and collection exhibition (Ploşniţă \& Ursu, 2011). The subject exhibition represents a branch of the historical specific, archaeologic, natural, ethnological, artistical historical, redesigned according to up-to-date scientifical level, at the same time being suggestive and emotional. The exposition must incapsulate a selection of museum pieces which are meaningful for the covered area and for represented specialty, must contain a subject and must represent its ideas using original and authentic masterpieces as well as additional and complementary exhibits. The thematic exhibition focuses the museum profile topics.

As consequence we infer that the permanent exhibition is the result of a titanic research, preservation, restauration effort of exposing the museum heritage. By design as being long term, the permanent exhibition carries a static feature and must meet some conditions, depending on the nature, thematic, socio-cultural requirements etc.

In contrast to permanent exhibition, the temporary exhibition can be designed by contribution of museums, physical persons, juridical persons or hobbyists. The temporary exhibition is deployed for short periods, but the impact over audience is a definitive one, and fascinating because of design, lighting, overall atmosphere build with help of interactive devices, multimedia technologies, sound effects. In context of our idea is stated that temporary exhibitions carry a dynamical load in contrast to permanent exhibitions that are steady, offering to audience the chance get in touch with the new revealed by the museum in connection to a historical event, cultural process, technical innovation, or a famous historical person (Postică, 2007).

The temporary museum exhibitions can be grouped as by (Galkina, 2004):

- belonging (owned, important and usual).

- driving technology (static and dynamic).

- exhibits componence (thematic, from museum stocks etc.).

- level of significance (regional, national, international).

Obviously, the experts of spotted areas decide the type of expositions intended to build and conduct inside the museum institution. They can opt for creation of exhibition composed of museum objects from museum patrimony, administered 
by them, but they can extend exhibition by borrowing valuable objects from other museums and private collections.

The mobile exhibition is a type of dynamic communication between the museum exhibit and audience via cultural-educational activity deployed in different areas and contexts. Via mobility and its interpretation, the mobile exhibition maximizes effects impacting the audience, facilitating message interchange, favoring the perception and implication in promoting the museum heritage (Toma, 2007).

Following that idea, the researchers mention that the museum exposed artefacts, the components of museum exhibition, must carry a whole common message aiming the most efficient contact with the audience (Anufriev, Șaherov, \& Șaherova, 2013; Ploșniță, 2010; Pop, 2016). The museum artefact selected for the exhibition must meet following communicative requirements:

- informative.

- suggestive.

- attractive.

This way we can conclude that each of listed requirements of museum object builds a suitable exposure environment meant to incite the active learning via perception and interactions between aimed audience and objects exposed in the museum facilities.

The grouping of objects that forms the museum exhibition is governed by following principles (Trojanskaya, 2007). Based on description of object grouping as citing the author, I develop the following diagram which reflects the quintessence of principles interconnection (Figure 2).

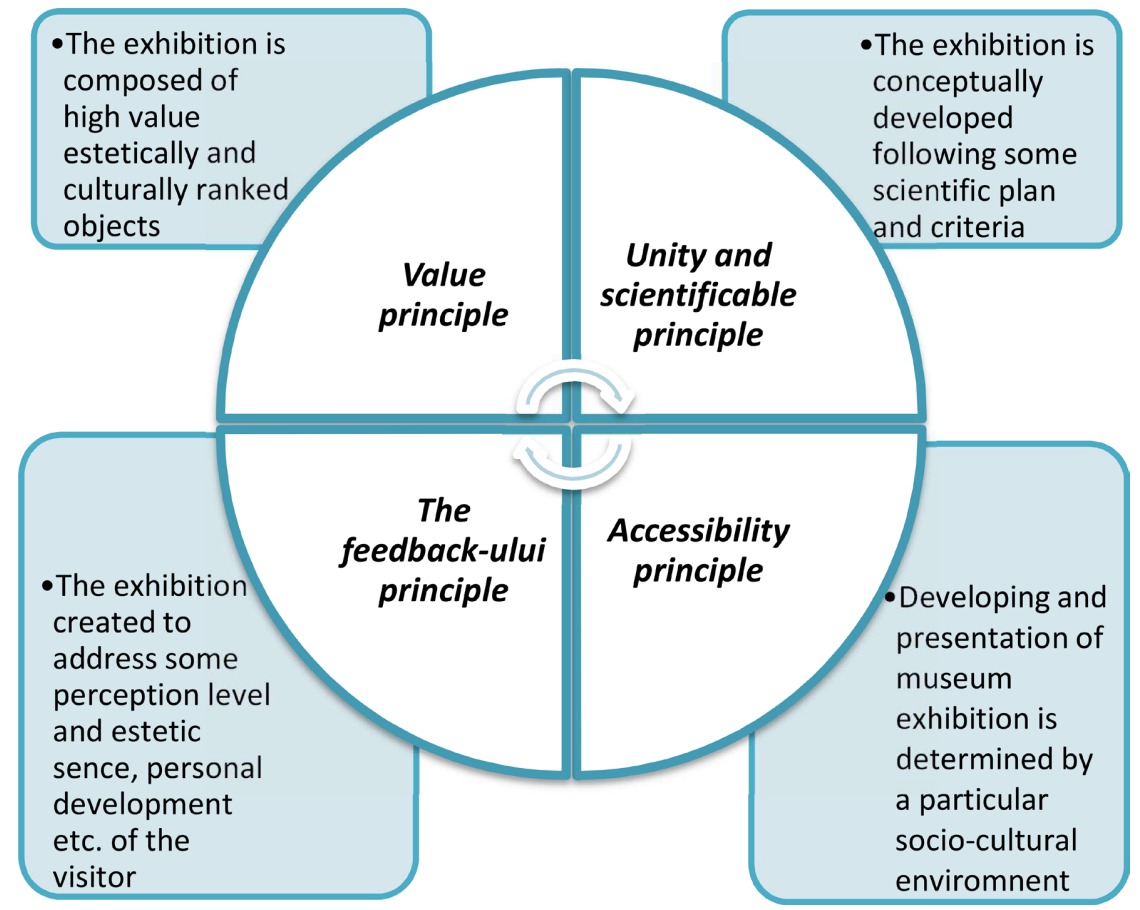

Figure 2. Principles of grouping of the objects, constituents of museum exhibition. 
Analyzing provided statements we can spot that the selection and assessment principles of the museum exhibition objects are highly important and reflects the interaction between the visitor and the museum heritage, these can be corelated to learning criteria as following:

- Stimulation of perceptive learning, this relates to different modifications in perception produced while visualizing and perceiving the museum exhibits. The children must be taught to perceive, i.e., to look, to analyze, to listen and to touch the perceived objects.

- Stimulation of verbal learning of formation and remembering of verbal connections as well as building and enrichening the vocabulary, revealing the semantic interconnectivities among words.

- Stimulation of motoring learning refers the acquisition if simple moves and their sequences which will be integrated in complex motoric abilities, which builds solving of different working tasks, sporting activities, choreography etc.

- Stimulation of concept learning is produced when the particular observer can make rational classification and understand the reasoning from of the root of this classification. The concepts are mental categories that people use for systemising the phenomena and the objects by following their common properties.

- Stimulation of social learning, which consists of the process of integration and social experience focused on standards, values, attitudes and behavioural patterns (Sălăvăstru, 2009).

Focusing the article subject with the provided above digest, is essential to specify that museum exhibition, developed according to psycho-pedagogic rigors, if well-structured, could establish an efficient perception, information processing stimulation and contribute to amelioration of the quality of the learning process. Following main idea, we underline some person organising and perception laws promoted by followers of gestalt theory meant to optimise the selection, grouping and interpretation of exhibition materials:

- Law of similarity: the elements which are similar in some ways (shape, colour, spaces, etc.) tends to be grouped in the same perceptive unity.

- Law of proximity: the elements that are most close to each other in space will be grouped in the same perceptive unity.

- Law of closure: elements that tends to integrate in a single entity are grouped together to form an enclosed form. More generally the closure has to be understood as tendency to avoid the blanks via some perceptive or intellectual activity.

- Law of continuity: the adjacent points tend to form a line, but the belonging of any point to particular line especially depends on capability of that point to extend that line.

- Law of optimal shapes: the elements suspected to be part of separated perception will be organised in more integral shapes based on symmetry, regu- 
larity and simplicity (Sălăvăstru, 2009).

The above laws of museum information perception assure the stimulus of student's cognition, triggers the thinking process developing, creativity and motivation of learning. The advanced experience of museum institution from Republic of Moldova facilitates the valorizing of museum education, focused on promoting the museum heritage to adult and adolescent audience via museum-school-entire community collaboration.

Emerging with exposed above we assess that if the museum exhibitions are built according to classification criteria of learning and according to conforming to specifics of ages of the audience these will amplify the impact of selected information and will assure the acquisition of relevant knowledge with respect to museum heritage.

Given the fact that museum exhibition is designed and conducted with the goal of educating of all categories of audience, the research of museum education (Aarts, 2010; Pop, 2016; Galkina, 2004; Trojanskaya, 2007), states that fulfilment of whole educational potential in the museum environment is feasible only by obeying following pedagogic requirements:

1) Organizational-methodologic, the coordination and establishing of museum objectives realized via museum environment, elaboration of educational program conducted in the museum environment, in concordance with overall cultural level of children and adults; the necessity of museum pedagogue to possess a vast area of knowledge and psycho-pedagogic abilities specific to museum activities;

2) Motivational, building the emotional comfort, contributing to positive perception of museum exhibition in the process of conducting the museum tours and activities, exposing the museum exhibits as models of developing the artistical activities focused on stimulation of artistic interest, cognition and;

3) Contextual, the introduction of exhibits and of the reconstruction of the historical events, in the educational process meant to contribute minimize the gap of cultural historical perception by children of the museum object, as social-historic and artistic symbol of human identity;

3) Procedural, minimizing the regulations of the process of education in the museum environment facilitates the free expression of ideas, emotions, feelings, building the improvising environment for gaming, diversity in interaction of museum area reported to museum objects.

In the scope of verifying the impact of museum exhibitions on the education of student's audience we developed and accomplished the Institutional partnership project in education, Creation of educational partnership in promoting the national and universal heritage from perspective of pupil's and student's museum education. The targeted project implied the educational and social institutions from Moldova Republic such as Ion Creangă State Pedagogical University, Technical University of Moldova, Theoretical Lyceum Ion Luca Caragiale from Orhei, National Museum of e Ethnography and Natural History from Chisinau, 
National Arts Museum of Moldova, the Academic International Center Eminescu from Chisinau, etc.

Given that the education process was reorganised due to pandemic crisis and turned into using the new informational technologies for a successful continuous teaching, we conducted the activities of museum education within the project by applying several online education platforms such as Google Classroom, Moodle, Zoom, Google Meet, Microsoft Teams.

Following the idea will be emphasized some good practices of museum education focused on promoting national and universal values, in the extracurricular online activities organised and conducted by us within the mentioned project.

Within the project: Creation of educational partnership in promoting the national and museum patrimony from the perspective of pupil's and student's museum education, we conducted an online round table activity dedicated to the National Day of Mărțișor, in this activity were involved the pupils of III, IV, V, IX, X degrees of the Theoretical Lyceum Ion Luca Caragiale from Orhei in conjunction with their parents and the didactic staff. The museologists from the National Museum of Ethnography and Natural History from Chisinau told to the pupils different versions of the Tale Of Mărțișor, the types and the styles of wearing this accessory inherited from our ancestors and transmitted through the growing generations. The pupils together with their parents manufactured one marțișor each and explored the heritage hosted by the National Museum of Ethnography and Natural History from Chisinau. Our manifestation was ended by organising an exhibition of the Mărțișors, manufactured by the pupils together with their parents.

The other two extracurricular activities conducted within the Institutional Project-Building the educational partnership in promoting the national and universal heritage from perspective of pupil's and student's museum education were dedicated to the national tapestry Secrets of the Moldovan rug.

The presented material and tasks for realization were selected according to age particularities of involved pupils, grades III, VII and XI, by the notorious specialists noted for valuable researches in museology, ethnology, artistic tapestry, in collaboration with the didactic staff of Theoretical Liceum Ion Luca Caragiale from Orhei. The pupils discovered interesting and curious things about the art of national tapestry, the modern tapestry, and the rugs collection of hosted by the National Museum of Ethnography and National History from Chisinau, sharing own knowledge found out from the parents or grandparents. Also, the pupils painted drawings with elements with elements national rug, especially designed with that purpose by students from Technical University of Moldova, the Faculty of Urbanism and Architecture, the Program of Interior Design, workings being included into an extraordinary exhibition.

As follows we will describe the other two activities of round table activity dedicated to the International Day of the book and the copyright, conducted as part of the same institutional project, with involving the pupils of III, IV, VII, X 
grades of the Theoretical Lyceum Ion Luca Caragiale from Orhei. These presentations and the working tasks were developed by us, the librarian specialists, the plastic artists, and students in collaboration with didactic staff from the lyceum. The pupils learned new and interesting things by watching the exhibition of Eminescian book hosted in the International Academic Centre Eminescu from Chisinau, also the newest books issued for children that can be found in the library. Meanwhile they acknowledged the books illustrated by and the biography of the most notorious artist of books for children, designer, and researcher of the urban architecture that led to a considerable developing of national culture, the master Lică Sainciuc. The pupils of gymnasium and lyceum schools built a bookmark each as part of the program CANVA, but the primary school pupils confectioned a bookmark each, elaborated and guided by students of the Technical University of Moldova, the Faculty of Urbanism and Architecture, the Interior Design program, exposed in a marvellous exhibition.

During the conducted activities we have applied following didactic forms:

- Round tables.

- Practical conferences.

- Virtual and physical excursions to museums.

- Exhibitions, works of pupils and students, etc.

Didactic methods:

- Demonstration.

- Exposition.

- Explanation.

- Observation.

- Conversation

- Learning through discovery

- Presentations, ppt, etc.

As consequence of the conducted activities of a 6-month period during our project we have accomplished a mini research, a pool of opinions of lyceum students, didactic staff and parents. We emphasize the most relevant results:

With the purpose of testing the impact of museum exhibition on the student's audience we've made s mini research, a pool of opinion of pupils, professors, and parents. By revealing the most relevant results:

- Vast majority of lyceums students, $83 \%$, shown high levels of interests and mentioned the envisioned exhibitions to be highly helpful in the deepening of historical, cultural and arts knowledge.

- $78 \%$ of lyceum students opted for conducting some lessons of history, Romanian language and literature, arts education inside the museum area.

- The professors, $86 \%$, emphasized the overall friendly environment and highly favorable possibilities for triggering the pupil's curiosity and interest in studying the museum exhibits as parts of conducted museum exhibitions.

- The parents, $91 \%$ pointed some tangible improvement in cognitive, esthetical, and moral behavior of their children-students involved in watching exhi- 
bitions.

As conclusion, we assert that each museum exhibition, developed and conducted in public or museum area is a great opportunity for developing and conducting activities of museum education focused on promoting the museum heritage to the adult and crescent generations. Meanwhile the collaboration between educational institutions and family is very important for all the actors involved in the education process.

As consequence of the above idea, we conclude that we accomplished good results both in museum education of students and the museum education of adults. Therefore, the students and adults' audience realized the fact that the museum institution plays a very important role in collecting, restoring, keeping the museum thesaurus and the promoting of the true national and universal values. The resulting of our mini research conducted in the Republic of Moldova we bring the following recommendations:

- The activation of museum education in within the schools and the entire community with active and creative implication of museum staff.

- Inclusion of museum education in the various programs and optional courses for all students and their parents.

- Establishing and maintaining a fructuous interoperability of school-museumfamily-community, where each of involved actors becomes an efficient partner in promoting the culture and museum thesaurus.

In the context of the research, we assert that each museum exhibition, designed and demonstrated in the public or museum area becomes an opportunity for developing and conducting the museum education activities focused on the promoting of museum heritage to the growing and adult generations, and the collaboration between educational institutions and family is highly important for all the actors involved in the process of education.

\section{Conflicts of Interest}

The author declares no conflicts of interest regarding the publication of this paper.

\section{References}

Aarts, H. (2010). What the Museum Is? The Museum Management and Education in Romania. The Museum Association of Netherlands.

Anufriev, A. V., Schacherov, V. P., \& Schacherova, S. L. (2013). The Museum Purpose and Protection of Cultural Heritage. Learning Tutorial. Publishing House ИГУ. 197 с. http://hist.isu.ru/ru/science/docs/shaherov anufriev.pdf

Galkina, T. V. (2004). Museology: Basics of Developing of Exhibition. Learning and Methodical Tutorial for Students of Students Majoring Historical Faculties, Specialization of Historical Museology and Local History. Publishing House of State Pedagogical University of Tomsk. $56 \mathrm{c}$.

Myagtina, N. V. (2010). Museology. Learning Tutorial for Students of Specialty 031502Museology. Publishing House Vladim of State University. 116 c. 
http://window.edu.ru/resource/348/77348/files/Uchebnoe-posobie-MUSEEVEDEIE.pd $\underline{\mathrm{f}}$

Ploșniță, E. (2010). Museum Institution and Evidence of Cultural Heritage. Issued in: Scientific Bullet, Ethnographic Magazine, Natural Science and Museology New Series vol. 13 (26) Chişinău, 344 p.

http://www.muzeu.md/buletin-stiintific/vol-13-26-chisinau-2010

Ploșniță, E., \& Ursu, M. (2011). Encyclopedia of Museology of Republic of Moldova (308 p.). Typography Bons Offices Chișinău.

Pop, R. S. (2016). Wide Access of Public to Museum Cultural Patrimony (200 p.). Ceconii.

Postică, I. (2007). Museum Exhibition as a Valorizing Tool of Archaeological Patrimony. Issued: Tyragetia, New Series, vol. I [XVI], nr. 2, History. Museology, Chişinău. https://www.nationalmuseum.md/ro/press releases/journal tyragetia/expozitia muzea la mijloc de valorificare a patrimoniului arheologic

Sălăvăstru, D. (2009). Psychology of Learning: Educational Theories and Practices (p. 74, 228 p.). Poliro.

Shcherbina, A. V. (2011). Museum Design. Learning-Methodical Tutorial. ТГУ. -68c. https://dspace.tltsu.ru/bitstream/123456789/359/1/\%D0\%A9\%D0\%B5\%D1\%80\%D0\% B1\%D0\%B8\%D0\%BD\%D0\%B0\%201-18-11.pdf

Toma, I. D. I. (2007). The Modern Museum: Educational Strategies. The European Institute; European.

Trojanskaya, S. L. (2007). Museum Pedagogy and Its Education Possibilities in the Building a Wide Cultural Competency. Learning Tutorial. Association Scientific Book. http://elibrary.udsu.ru/xmlui/bitstream/handle/123456789/9940/2012566.pdf?sequence $=1$ 